\title{
Pain in Patients with Dystrophic Epidermolysis Bullosa: Association with Anxiety and Depression
}

\author{
Giulio Fortuna ${ }^{1,2,3} \bowtie$, Massimo Aria ${ }^{4}$, Rodrigo Cepeda-Valdes ${ }^{2}$, \\ Maria Guadalupe Moreno Trevino ${ }^{5}$, and Julio Cesar Salas-Alanís ${ }^{2,5}$ \\ ${ }^{1}$ Department of Diagnostic Science, Louisiana State University School of Dentistry, LA, USA \\ ${ }^{2}$ Dystrophic Epidermolysis Bullosa Research Association Mexico Foundation, Nuevo Leon, Mexico \\ ${ }^{3}$ Federico Navarro Institute-School of Orgonomy "Piero Borrelli", Naples, Italy \\ ${ }^{4}$ Department of Economics and Statistics, Federico II University of Naples, Naples, Italy \\ ${ }^{5}$ Department of Basic Science, Universidad de Monterrey, Nuevo Leon, México
}

\begin{abstract}
Objective We investigate the presence and the quality of pain in patients with dystrophic epidermolysis bullosa (DEB), and its correlation with the level of anxiety and depression.

Methods We collected data from 27 DEB patients and 26 healthy individuals. DEB patients and controls completed 1 scale for the quality of pain, and 1 scale for anxiety and depression. Pain was assessed with the short form of the McGill Pain Questionnaire, whereas anxiety and depression were assessed with the Hamilton rating scale for anxiety and depression.

Results DEB patients and healthy control individuals were homogeneous for age and gender $(\mathrm{p}>0.05)$. A statistically significant difference in the two groups was seen for sensory pain rating scale $(\mathrm{p}<0.001)$, affective pain rating scale $(\mathrm{p}=0.029)$, total pain rating scale $(\mathrm{p}<0.001)$, visual analogue scale $(\mathrm{p}=0.012)$ and present pain intensity $(\mathrm{p}=0.001)$, but not for anxiety $(\mathrm{p}=0.169)$ and depression $(\mathrm{p}=0.530)$. The characteristics of pain that showed a significant difference between DEB patients and healthy controls were shooting, splitting, tender and throbbing $(\mathrm{p}<0.05)$. In DEB patients pain was not correlated with anxiety or depression $(\mathrm{p}>0.05)$, whereas a slight correlation between pain and anxiety was found in healthy controls $(\mathrm{p}<0.05)$. No difference was found between quality of pain and anxiety-depression in DEB patients ( $p>0.05$ ), but was between the DEB dominant and the recessive form of DEB ( $\mathrm{p}=0.025)$.

Conclusion The perception of pain in DEB patients appears greater than in healthy individuals, with splitting and tender characteristics being the most significant ones, but was not associated with anxious and/or depressive symptoms.
\end{abstract}

Psychiatry Investig 2017;14(6):746-753

Key Words EB, Epidermolysis bullosa, Pain, Anxiety and depression.

\section{INTRODUCTION}

Epidermolysis bullosa (EB) is a genetic disorder characterized by mucocutaneous fragility with subsequent formation of blisters after friction or mild mechanical trauma., ${ }^{1,2}$

$\mathrm{EB}$ can be inherited in either autosomal dominant or recessive fashion. There are four major types of EB (and many subtypes) based on the ultrastructural level of separation of the

Received: August 19, 2016 Revised: December 6, 2016

Accepted: December 31, 2016 Available online: August 29, 2017

$\triangle$ Correspondence: Giulio Fortuna, DMD, PhD

Department of Diagnostic Sciences, Louisiana State University School of Dentistry, 1100 Florida Ave, New Orleans, LA 70119, USA

Tel: +1-504-941-8330, Fax: +1-504-941-8336, E-mail: giulio.fortuna@gmail.com

(c) This is an Open Access article distributed under the terms of the Creative Commons Attribution Non-Commercial License (http://creativecommons.org/licenses/bync/4.0) which permits unrestricted non-commercial use, distribution, and reproduction in any medium, provided the original work is properly cited. epidermis from the underlying dermis: intraepidermal (Simplex type), intralamina lucida (Junctional type), sublamina densa (Dystrophic type), mixed (kindler syndrome). ${ }^{2}$

The etiopathogenesis of all forms of EB resides in mutations in more than 10 different genes coding for mutated proteins located at different levels in the epidermis/dermis. Indeed, mutations in Transglutaminase 5, Plakoglobin, Plakiphilin 1 and Demosplakin will be responsible for the suprabasal form of EB Simplex (EBS); mutations in Keratins 5/14, Plectin, BP230, Kindlin-1, Exophilin 5 will be responsible for the basal form of EBS; mutations in Integrins $\alpha 6 \beta 4$, Integrin $\alpha 3$, Collagen XVII, and Laminin-322 will be responsible for the Junctional form of EB (JEB), and, lastly, mutations in type VII Collagen will be responsible for both dominant and recessive forms of Dystrophic EB (DEB). ${ }^{2}$

Due to its multi-systemic involvement and extremely vari- 
able clinical phenotype (from very severe and life-threatening to very mild form), ${ }^{1}$ pain may be a constant and very tough experience for $\mathrm{EB}$ patients, mostly for those ones with the more devastating phenotype, ${ }^{3}$ highly affecting their quality of life. ${ }^{4,5}$

Pain is defined by the International Association of the Study of Pain as "an unpleasant sensory and emotional experience associated with actual or potential tissue damage, or described in terms of such damage", ${ }^{6}$ and in case of EB it usually derives from cutaneous, or bone/joints, or gastrointestinal involvement as well as surgical procedure. ${ }^{3}$ Such patients may feel pain due to the constant presence of blisters/erosions on the skin, ${ }^{1,2}$ oral cavity, ${ }^{7-9}$ ano-genital tract, ${ }^{10}$ and eyes. ${ }^{11}$ The feel also pain during their daily activities, like bath, dress changing, ${ }^{12}$ and urination, ${ }^{3}$ or during procedures, like hand or esophageal ${ }^{13}$ as well as cancer resection surgery. ${ }^{3}$

Therefore, studies on EB patients have become more and more important over time, due to the high impact on their psycho-social life: indeed EB seems to greatly affect not only the quality of life of these patients, ${ }^{4,5}$ but also their economic status, ${ }^{14}$ and their related family members and care-givers' life, ${ }^{15}$ as well as their psychological asset. ${ }^{16}$ Nonetheless, different results have been published regarding this last aspect..$^{17,18}$

Because the experience of pain still remains subjective and varies from individual to individual, the management of pain in $\mathrm{EB}$ can be complex and challenging ${ }^{12}$ requiring very often a multidisciplinary approach. It usually includes topical and systemic treatment, and possibly nonpharmacological therapies. ${ }^{3}$

Over the past few decades, pain has been evaluated via both numerical rating scale ${ }^{19}$ or visual analogue scale ${ }^{20}$ or questionnair ${ }^{21}$ and the majority of them have mainly addressed the pain management. Therefore, to the best of our knowledge, it seems that no data is currently available in the literature regarding the characteristics of pain in patients with DEB.

As the pain in EB seems to be more representative in patients carrying the dystrophic type ${ }^{19}$ we decided to perform a crosssectional study in order to determine the quality of pain in patients with DEB versus a control group, and correlate it with the level of anxiety and depression.

\section{METHODS}

\section{Study design and patients}

We collected data from 27 DEB patients and 26 healthy individuals, as a control group, coming from the Epidermolysis bullosa clinic from Dystrophic Epidermolysis Bullosa Research Association (D.eb.R.A.), Mexico. All patients provided their written informed consent. The ethical committee of the Universidad Autonoma de Monterrey (UDEM) approved this cross-sectional study.

We included patients of both gender, aged 16 or older, all race, whose diagnosis of DEB and differentiation between dominant (DDEB) and recessive (RDEB) form were based on clinical criteria and skin biopsy with a routine histology and immunofluorescence antigen mapping, and/or, whereas available, electron microscopy, and/or DNA analysis, ${ }^{2}$ and were able to give consent if older than 18 years.

Similarly, we included healthy individuals of both genders aged 16 or older, of all races, who worked at the EB clinic as volunteers or were caregivers and who had no other muco-cutaneous diseases, such as lichen planus, eczema, atopic dermatitis, and were able to give consent if older than 18 years. For minor patients, in both groups, consent was provided by their parents or legal guardians.

Exclusion criteria for both groups encompassed patients with psychiatric illness, organic brain syndrome or neurological disease, history of drug abuse, patients regularly treated with psychoneuropharmacological treatment, such as antidepressants, anticonvulsivants, antianxiety or psychotropic drugs or with opioid and non-opioid analgesic medications, because the short form of the McGill Pain Questionnaire (SF$\mathrm{MPQ}$ ) is sensitive to clinical changes induced by analgesics. ${ }^{22}$ Patients were also excluded if they presented with impaired consciousness, any degree of visual impairment, or lack of the necessary communication skills to ensure the reliability of tests.

Two specialists were responsible for every patient who received a medical anamnesis (past, present, family and social), a general medical examination, and an intra and extraoral examination.

Upon admission, specific psychometric instruments (see below) in Spanish versions ${ }^{23-25}$ were employed, which were reviewed for completeness before collection.

\section{Psychometric instruments: evaluation of anxiety- depressive symptoms and self-esteem}

\section{Short form of the McGill Pain Questionnaire}

SF-MPQ ${ }^{22}$ was used as an index of pain severity and quality. The SF-MPQ is made up of 15 descriptive adjectives for the pain sensation (11 sensory and 4 affective) which were self-rated by the patient according to their intensity level on a point rating scale ( $0=$ none, $1=$ mild, $2=$ moderate, $3=$ severe) plus 1 item for present pain intensity (PPI), and 1 item for visual analog scale (VAS). ${ }^{26}$

In total, we have five scores derived from the SF-MPQ: the Sensory Pain Rating Index (S-PRI), calculated by summing the first 11 pain adjectives (range 0 to 33); the Affective Pain Rating Index (A-PRI), calculated by summing the 4 last pain adjectives (range 0 to 12), and Total Pain Rating Index (T-PRI), calculated by adding together the S-PRI and the A-PRI (range 
0 to 45$)$. SF-MPQ also includes the Visual Analogue Scale (VAS), that uses a $10-\mathrm{cm}$ line divided into $1-\mathrm{cm}$ sections, where patients indicate their level of pain by marking the appropriate place on the scale from 0 (no pain) to 10 (the worst possible pain), and the Present Pain Intensity (PPI), where patients indicate their current level of pain ranging from $0=$ no pain to $5=$ excruciating. VAS and PPI were both used to provide indices of overall pain intensity. ${ }^{27}$

SF-MPQ provides a quick assessment when time is limited, taking 2-5 minutes to complete, ${ }^{28}$ and therefore, this helped in minimizing the respondent burden.

\section{Hamilton rating scale for anxiety}

This scale consists of 14 items, each defined by a series of symptoms. It is used to determine the anxiety levels and the distribution of symptoms of patients. Each cluster of symptoms is rated on a five-point scale running from grade 0 (none), 1 (mild), 2 (moderate intensity), 3 (severe), to grade 4 (very severe or grossly disabling), with a total score range of $0-56$, with higher scores indicating higher levels of anxiety. ${ }^{29}$ A score of 7 indicates an absence/minimal anxiety, scores of 8 to 14 represent mild, 15 to 23 moderate, and $\geq 24$ severe anxiety. ${ }^{30}$

\section{The Hamilton Rating Scale for Depression}

The HAM-D contains 21 ratings measured on three ( 0 to 2 ) or five ( 0 to 4 ) point scales. The first 17 items are used in scoring the instrument. Eight items $(4,5,6,12,13,14,16,17)$, dif- ficult to quantify, are rated grossly on a 0 to 2 scale: $0=$ symptom absent, $1=$ slight or doubtful, and $2=$ clearly present. Nine items $(1,2,3,7,8,9,10,11,15)$ are graded more finely on a 0 to 4 scale in terms of increasing intensity: $0=$ symptom absent, $1=$ doubtful or trivial, $2=$ mild, $3=$ moderate, and $4=$ severe. Scores can range from 0 to $52 .{ }^{31} \mathrm{~A}$ total score is computed reflecting the degree of symptom severity. Hamilton did not specify cuttingpoints, but it is generally agreed that scores lower than 7 indicate an absence of depression, scores of 8 to 16 represent mild, 17 to 23 moderate, and $\geq 24$ severe depression. ${ }^{32}$

\section{Statistic analysis}

Descriptive statistics of socio-demographic characteristics of DEB patients and healthy controls were calculated as mean \pm standard deviation, frequency, and medians with interquartile range. An exact $t$ test and Pearson's chi-squared test were employed for categorical variables. Difference of medians of all clinical parameters (pain and anxiety) between DEB patients and healthy individuals as well as difference of medians of pain between the types of DEB were calculated by Mann-Whitney $\mathrm{U}$ test. The difference in quality of pain was conversely calculated using exact Fisher's test. Linear correlation between quality of pain and anxiety and depression was measured by Spearman's rank correlation coefficient ( $\mathrm{r}$ ). $\mathrm{p}$-values were considered significant if $0.01<\mathrm{p} \leq 0.05$ and highly significant if $\leq 0.01$.

Table 1. Demographics and clinical characteristics of samples

\begin{tabular}{lccc}
\hline \multicolumn{1}{c}{ Demographic variables } & Patients $(\mathrm{N}=27)$ & Healthy controls $(\mathrm{N}=26)$ & $\mathrm{p}$-value \\
\hline Age (mean \pm SD) & $31.5 \pm 11.4$ & $30.4 \pm 9.6$ & 0.697 \\
Gender (male:female) & $9: 18$ & $9: 17$ & 0.922 \\
DEB type (\%) & & - & - \\
DDEB-gen & $3(11.1)$ & & \\
DDEB-Pr & $5(18.5)$ & & \\
RDEB-gen int & $5(18.5)$ & Median (IQR) & $<0.001^{\dagger}$ \\
RDEB-gen sev & $14(51.9)$ & $3.00(1.00-6.00)$ & $0.029^{*}$ \\
Clinical parameters & Median (IQR) & $2.50(0.50-4.50)$ & $<0.001^{\dagger}$ \\
S-PRI & $11.0(8.00-20.00)$ & $3.00(1.00-5.00)$ & $0.012^{*}$ \\
A-PRI & $10.5(7.75-11.00)$ & $0.60(0.00-1.48)$ & $0.001^{\dagger}$ \\
T-PRI & $11.0(8.00-19.00)$ & $0.00(0.00-1.00)$ & 0.169 \\
VAS & $1.80(0.10-4.00)$ & $4.50(2.00-12.25)$ & $3.50(0.75-9.00)$ \\
PPI & $1.00(0.00-2.00)$ & & 0.530 \\
HAM-A & $11.00(2.00-16.00)$ & $4.00(0.00-8.00)$ & \\
HAM-D & & & \\
\hline
\end{tabular}

*significant $0.01<\mathrm{p} \leq 0.05$, thighly significant $\mathrm{p} \leq 0.01$. DDEB-gen: dominant dystrophic epidermolysis bullosa generalized, DDEB-Pr: dominant dystrophic epidermolysis bullosa pruriginosa, RDEB-gen int: recessive dystrophic epidermolysis bullosa generalized intermediate, RDEB-gen sev: recessive dystrophic epidermolysis bullosa generalized severe, S-PRI: Sensory Pain Rating Index, A-PRI: Affective Pain Rating Index, T-PRI: Total Pain Rating Index, VAS: visual analogue scale, PPI: present pain intensity, HAM-A: Hamilton Rating Scale for Anxiety, HAM-D: Hamilton Rating Scale for Depression 


\section{RESULTS}

\section{Socio-demographic and clinical characteristics}

We enrolled 27 patients (9 males and 18 females) with DEB in the study with mean age of $31.5 \pm 11.4$ and 26 healthy individuals (9 males and 17 females) with mean age of 30.4 \pm 9.6 . No statistical difference was noted between DEB patients versus control group in terms of age $(\mathrm{p}=0.697)$, gender $(\mathrm{p}=0.922)$, anxiety $(\mathrm{p}=0.169)$ and depression $(\mathrm{p}=0.530)$. In the group of DEB patients, the majority of patients were affected by the severe generalized recessive form (51.9\%) (Table 1).

\section{Pain perception and quality of pain}

The analysis of pain measured with SF-MPQ revealed that DEB patients perceive greater pain than healthy individuals in terms of intensity (VAS, $\mathrm{p}=0.012$ and PPI, $\mathrm{p}=0.001$ ) (Table 1 , Figure 1$)$ and quality of pain sensory scale (S-PRI) $(\mathrm{p}<0.001)$ and affective subscale (A-PRI) $(\mathrm{p}=0.029)$ (Table 1, Figure 2). Among all different qualities of pain, a difference between the two group was only seen in throbbing $(\mathrm{p}=0.035)$, shooting $(\mathrm{p}=0.014)$, tender $(\mathrm{p}=0.004)$, and splitting $(\mathrm{p}=0.005)$ (Table 2 , Figure 3).

\section{Correlation of pain with and anxiety/depression}

The analysis of correlation of VAS and PPI with HAM-A and HAM-D showed that in the DEB patients VAS and PPI correlate with each other $(\mathrm{p}<0.001)$, but they do not correlate with anxiety and depression ( $p>0.05)$, whereas anxiety does corre-

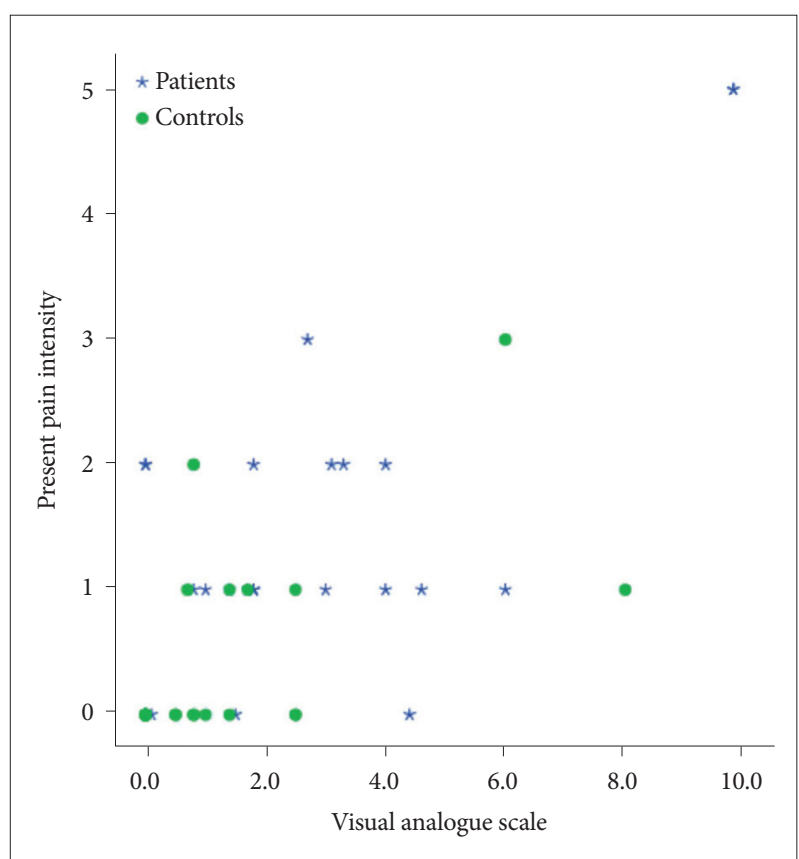

Figure 1. Comparison of intensity of pain via present pain intensity and visual analogue scale between dystrophic epidermolysis bullosa patients and healthy controls. late with depression $(\mathrm{p}<0.001)$. On the other hand, in the control group, VAS and PPI seems to slightly correlate with anxiety ( $\mathrm{p}=0.020$ and 0.032 , respectively) (Table 3 ). Additionally, the analysis of correlation between each single quality of pain and anxiety and depression failed to demonstrate any statistical significant result ( $\mathrm{p}>0.05)$ (Table 4).

Lastly, level of pain measured by VAS showed a difference between the dominant and recessive form of DEB $(p=0.025)$ (Table 5).

\section{DISCUSSION}

Pain plays a major role in EB patients' life, representing a tough challenge, as it may be constant even during routine daily activities.

Several papers have been published over the past 20 years regarding the pharmacological and non-pharmacological management of pain in $\mathrm{EB},{ }^{3,12,13}$ but no data about the characteristics of pain in patients with EB is currently present in the literature. Therefore, this seems to be the first cross-sectional study reporting on the quality of pain in a cohort of patients with one of the three major types of EB, the dystrophic one, in an attempt to provide additional information on how to better manage pain in DEB patients.

We analyzed a sample of 27 patients with DEB and 26 healthy individuals, that turned out to be homogenous in terms of age, gender and anxiety and depression status ( $\mathrm{p}>0.05)$ (Table 1$)$.

The quality of pain in patients with DEB was measured using a well-known and validated tool, SF-MPQ.

In patients with DEB, SF-MPQ showed that both the senso-

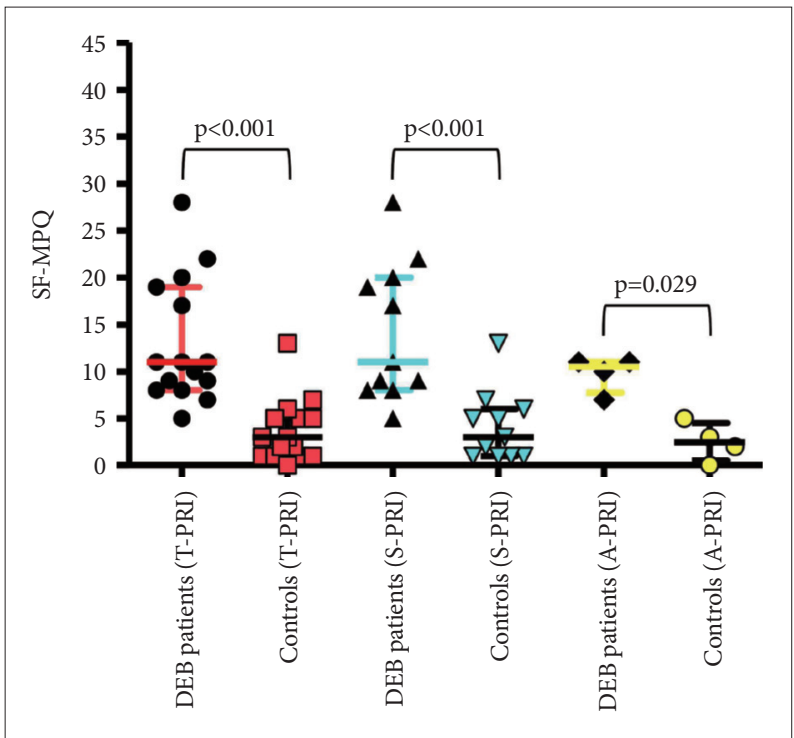

Figure 2. Comparison of quality of pain via sensory, affective, and total pain rating index between DEB patients and healthy controls $(p<0.05$, Mann-Whitney U test). SF-MPQ: short form of the McGill Pain Questionnaire, DEB: dystrophic epidermolysis bullosa. 
ry and affective components were more impaired than in the healthy controls $(p<0.001$ and $p=0.029$, respectively). Similarly, even the intensity of pain measured with VAS and PPI showed a statistical significant difference between DEB and healthy individuals ( $\mathrm{p}=0.012$ and $\mathrm{p}=0.001$, respectively) (Table 1). However, interestingly, the level of pain in DEB was not so high as expected with a median of 1.80 (range, 0.10-4.00) for VAS and a median of 1.00 (range, $0.00-2.00$ ) for PPI (Table 1). The stratification by $\mathrm{DEB}$ form demonstrated that the level of pain measured with VAS was much higher in patients with the recessive form than in those with the dominant one (median 2.70 vs. 0.45 , respectively; $\mathrm{p}=0.025$ ) (Table 4 ), although the sample size between the 2 forms was not homogenous (Table 1).

We also calculated the presence/absence of a specific type of pain showing difference in intensity between the 2 groups (Figure 1). Our analysis demonstrated that only 4 different quality of pain (tender, splitting, throbbing, and shooting) were

Table 2. Difference in quality of pain between DEB patients and healthy controls

\begin{tabular}{|c|c|c|c|c|c|}
\hline \multirow{2}{*}{ Quality of pain } & \multicolumn{2}{|c|}{ DEB patients with pain } & \multicolumn{2}{|c|}{ Healthy controls with pain } & \multirow{2}{*}{ p-valu } \\
\hline & Yes $(\%)$ & No $(\%)$ & Yes $(\%)$ & No $(\%)$ & \\
\hline Throbbing & 44.4 & 55.6 & 15.4 & 84.6 & $0.035^{*}$ \\
\hline Shooting & 44.4 & 55.6 & 11.5 & 88.5 & $0.014^{*}$ \\
\hline Stabbing & 18.5 & 81.5 & 3.8 & 96.2 & 0.192 \\
\hline Sharp & 11.1 & 88.9 & 3.8 & 96.2 & 0.610 \\
\hline Cramping & 18.5 & 81.5 & 26.9 & 73.1 & 0.526 \\
\hline Gnawing & 18.5 & 81.5 & 7.7 & 92.3 & 0.420 \\
\hline Hot-burning & 25.9 & 74.1 & 11.5 & 88.5 & 0.294 \\
\hline Aching & 18.5 & 81.5 & 0.0 & 100.0 & 0.197 \\
\hline Heavy & 44.4 & 55.6 & 26.9 & 73.1 & 0.254 \\
\hline Tender & 59.3 & 40.7 & 19.2 & 80.8 & $0.004^{\dagger}$ \\
\hline Splitting & 37.0 & 63.0 & 3.8 & 96.2 & $0.005^{\dagger}$ \\
\hline Tiring-exhausting & 18.5 & 81.5 & 15.4 & 84.6 & 1.000 \\
\hline Sickening & 25.9 & 74.1 & 7.7 & 92.3 & 0.142 \\
\hline Fearful & 22.2 & 77.8 & 3.8 & 96.2 & 0.100 \\
\hline Punishing-cruel & 11.1 & 88.9 & 0.0 & 100.0 & 0.236 \\
\hline
\end{tabular}

*significant $0.01<\mathrm{p} \leq 0.05$, thighly significant $\mathrm{p} \leq 0.01$. DEB: dystrophic epidermolysis bullosa

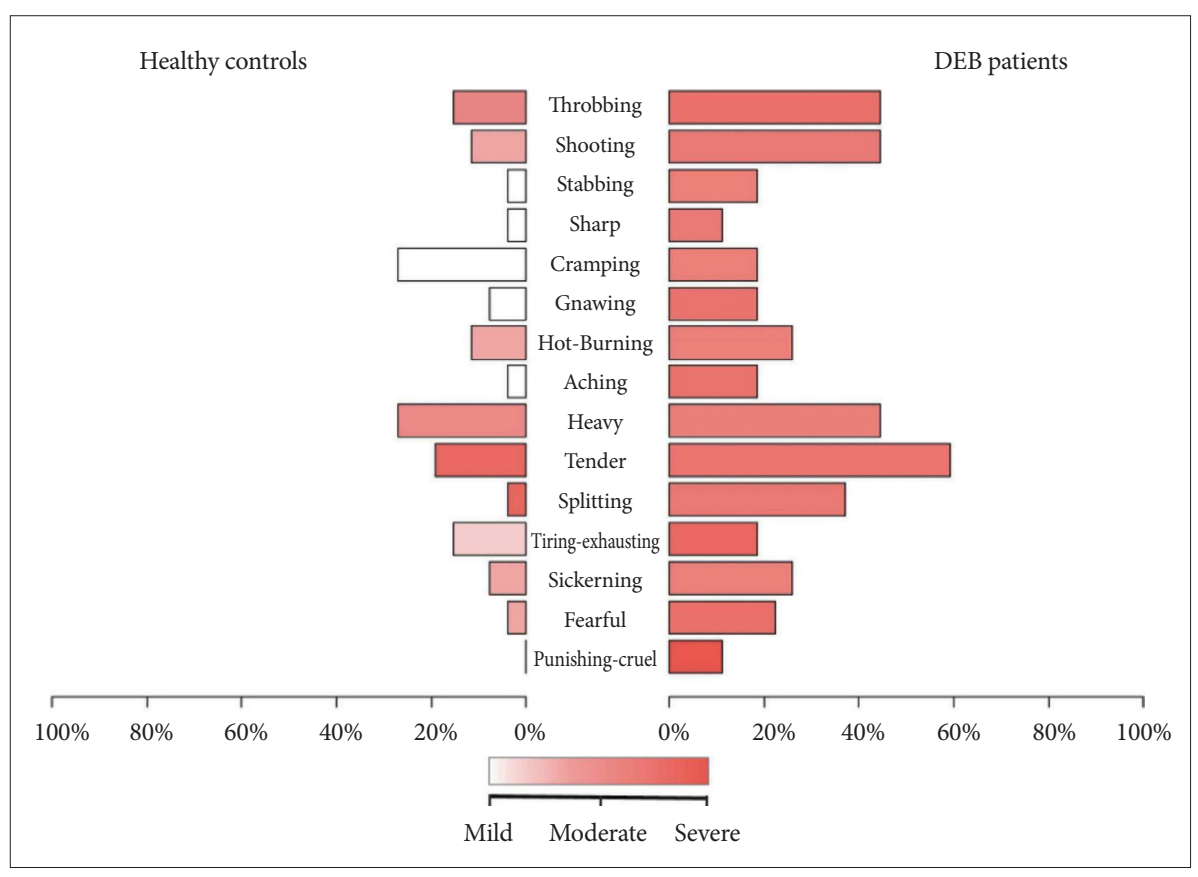

Figure 3. Comparison of quality of pain via colored gradient bars between DEB patients and healthy controls. DEB: dystrophic epidermolysis bullosa. 
Table 3. Correlation between VAS and PPI with anxiety and depression in DEB patients and control group

\begin{tabular}{llcc}
\hline & \multicolumn{1}{c}{ VAS } & PPI & HAM-A \\
\hline DEB patients & & & \\
VAS & $0.727(<0.001)^{\dagger}$ & \\
PPI & $0.163(0.416)$ & $0.118(0.558)$ & $0.720(<0.001)^{\dagger}$ \\
HAM-A & $0.278(0.168)$ & $0.135(0.503)$ & \\
HAM-D & & & \\
Healthy controls & $0.607(<0.001)^{\dagger}$ & & $0.759(<0.001)^{\dagger}$ \\
VAS & $0.454(0.020)^{*}$ & $0.197(0.334)$ & \\
PPI & $0.301(0.136)$ & & \\
HAM-A & & & \\
HAM-D & & & \\
\hline
\end{tabular}

*significant $0.01<\mathrm{p} \leq 0.05$, thighly significant $\mathrm{p} \leq 0.01$. VAS: visual analogue scale, PPI: present pain intensity, HAM-A: Hamilton Rating Scale for Anxiety, HAM-D: Hamilton Rating Scale for Depression

Table 4. Correlation between quality of pain and anxiety/depression in DEB patients

\begin{tabular}{lcccc}
\hline \multirow{2}{*}{ Quality of pain } & \multicolumn{2}{c}{ HAM-A } & & \multicolumn{2}{c}{ HAM-D } \\
\cline { 2 - 3 } \cline { 5 - 5 } Throbbing & Correlation coefficient & p-value & Correlation coefficient & 0.979 \\
Shooting & 0.256 & 0.198 & 0.005 & 0.871 \\
Stabbing & 0.038 & 0.850 & 0.033 & 0.928 \\
Sharp & 0.109 & 0.587 & -0.018 & 0.486 \\
Cramping & 0.051 & 0.802 & -0.140 & 0.150 \\
Gnawing & -0.173 & 0.388 & -0.285 & 0.791 \\
Hot-burning & 0.205 & 0.305 & -0.054 & 0.401 \\
Aching & -0.083 & 0.679 & -0.168 & 0.401 \\
Heavy & 0.152 & 0.450 & 0.168 & 0.819 \\
Tender & 0.258 & 0.194 & 0.046 & 0.256 \\
Splitting & 0.266 & 0.179 & 0.226 & 0.559 \\
Tiring-exhausting & 0.246 & 0.217 & 0.118 & 0.569 \\
Sickening & 0.129 & 0.521 & 0.115 & 0.401 \\
Fearful & 0.000 & 1.000 & 0.168 & 0.219 \\
Punishing-cruel & 0.205 & 0.822 & 0.245 & 0.785 \\
\hline
\end{tabular}

HAM-A: Hamilton Rating Scale for Anxiety, HAM-D: Hamilton Rating Scale for Depression

Table 5. Difference in pain measured by visual analogue scale between the two DEB subtypes

\begin{tabular}{lcc}
\hline \multicolumn{1}{c}{ DEB type } & Median (IQR) & p-value \\
\hline DDEB & $0.45(0.00-1.73)$ & $0.025^{*}$ \\
RDEB & $2.70(1.40-4.40)$ & \\
\hline
\end{tabular}

*significant $0.01<\mathrm{p} \leq 0.05$. DDEB: dominant dystrophic epidermolysis bullosa, RDEB: recessive dystrophic epidermolysis bullosa

significant between DEB patients and healthy individuals (Table 2). No statistical analysis for intensity of pain was performed because the sample size was too small. These results are probably not surprising given the nature of this disease. Indeed, the highly significant difference into the sensory cat- egory (tender and splitting) might be explained by the fact that the skin in DEB patients is too thin or even absent, making this kind of pain predominant. Interestingly, DEB patients report a perception of pain also into the temporal category (throbbing) and into the spatial category (shooting), meaning that their pain can be waxing and waning and so severe to start in one place then quickly move to another.

As chronic pain condition can influence mood states, leading to the development of depressive symptoms, ${ }^{33}$ we decided to measure the level of anxiety/depressive symptoms in DEB patients, trying to correlate them with the intensity of pain. As different scales for anxiety and depression have demonstrated to provide the same information, ${ }^{18}$ we decided to choose 
just one, that was, Hamilton for anxiety and depression administered by a physician with a background in psychotherapy.

The analysis of intensity of pain and psychometric battery scales failed to demonstrate any correlation between pain and anxiety/depression in DEB patients ( $\mathrm{p}>0.05)$, unlike healthy individuals, where a weak-but statistically significant-correlation was found between pain and anxiety (Table 3). We do not know why we obtained this paradoxical finding; we may hypothesized that 2 factors were implicated: 1) the cross-sectional nature of the study and 2) the presence of pain since birth for the majority of DEB patients, making them used to it. Therefore, they might have a less likelihood of developing anxiety because of pain.

Therefore, we may conclude that DEB patients experience more pain than healthy individuals with splitting and tender characteristics being the most significant ones and that pain in DEB patients does not correlate with anxious/depressive symptoms.

It is also important to highlight that our results showed some limitations including the small sample size, the restriction to just one EB type, and the analysis of the psychological (anxiety and depression), the sensory and affective aspect of the pain (SF-MPQ) only. In fact, we now know that pain is widely conceived as a biopsychosocial phenomenon that is influenced not only by biological (e.g., injury, infection), psychological (e.g., negative mood), but also by cognitive, behavioral and socio-ethnocultural factors, that can dynamically interact to influence a person's overall experience of pain. ${ }^{34}$

Additionally, we need to underline that all DEB patients were coming from Northern Mexico and were young adults over the age of 16 , whose level pain was unexpectedly quite low and easily manageable with acetaminophen even for those activities considered to be the most painful ones, like bath and changing bandages. However, we do not know whether we could get the same results from an EB pediatric population. This aspect should be further investigated by using appropriate psychometric scales designed for pediatric patients to test both anxiety/depression, like the Revised Child Anxiety and Depression Scales, ${ }^{35}$ and intensity/quality of pain, like the faces pain rating scale, the colored analogue scale ${ }^{36}$ or the cloudy ranking scale. ${ }^{37}$

Due to the small sample size, the relatively low level of anxiety and depression with unexpectedly quite low level of pain, our results should be interpreted with caution. Therefore, it would be interesting to perform multicenter studies in different countries of the world on a larger sample of patients with different types of EB, different ethnic and genetic background, in order to confirm our results.

We believe that the evaluation of the quality of pain was the most important and unique aspect of our study, as this might have some implications in driving our therapeutic choice when managing pain in DEB patients. The main goal would be to try to understand whether or not we might have a more targeted pain management based on a specific type of pain. Indeed, pain management includes different therapeutic options, not just opioid analgesics that are widely used in EB patients. ${ }^{38}$ Whether these other options, such as anticonvulsants and antidepressant, may be employed to obtain a better analgesia in patients with EB patients, mostly RDEB, still remains an open question and, therefore, clinical trials, possibly randomized controlled ones, should be performed in the near future.

\section{Acknowledgments}

We are very grateful to all DEB patients for their courage, strength, and love. We would like to thank all DebRA Mexico, Monterrey, particularly Lic. Erika Salas for her valuable and priceless assistance.

\section{REFERENCES}

1. Pai S, Marinkovich MP. Epidermolysis bullosa: new and emerging trends. Am J Clin Dermatol 2002;3:371-380.

2. Fine JD, Bruckner-Tuderman L, Eady RA, Bauer EA, Bauer JW, Has C, et al. Inherited epidermolysis bullosa: updated recommendations on diagnosis and classification. J Am Acad Dermatol 2014;70:1103-1126.

3. Goldschneider KR, Lucky AW. Pain management in epidermolysis bullosa. Dermatol Clin 2010;28:273-282, ix.

4. Tabolli S, Sampogna F, Di Pietro C, Paradisi A, Uras C, Zotti P, et al. Quality of life in patients with epidermolysis bullosa. Br J Dermatol 2009;161:869-877.

5. Horn HM, Tidman MJ. Quality of life in epidermolysis bullosa. Clin Exp Dermatol 2002;27:707-710.

6. Merskey H, Lindblom U, Mumford JM, Nathan P, Sunderland S. Part III: Pain Terms, A Current List with Definitions and Notes on Usage. In: Merskey H, Bogduk N, Editor. Classification of Chronic Pain, Descriptions of Chronic Pain Syndrome and Definitions of Pain Terms. Second Edition. Seattle: IASP Press, 1994, p.210.

7. Fortuna G, Lozada-Nur F, Pollio A, Aria M, Cepeda-Valdes R, Marinkovich MP, et al. Patterns of oral mucosa lesions in patients with epidermolysis bullosa: comparison and agreement between oral medicine and dermatology. J Oral Pathol Med 2013;42:733-740.

8. Fortuna G, Aria M, Cepeda-Valdes R, Pollio A, Moreno-Trevino MG, Salas-Alanis JC. Clinical features of gingival lesions in patients with dystrophic epidermolysis bullosa: a cross-sectional study. Aust Dent J 2015;60:18-23.

9. Wright JT. Oral manifestations in the epidermolysis bullosa spectrum. Dermatol Clin 2010;28:159-164.

10. Fine JD, Mellerio JE. Extracutaneous manifestations and complications of inherited epidermolysis bullosa: part I. Epithelial associated tissues. J Am Acad Dermatol 2009;61:367-384; quiz 85-86.

11. Figueira EC, Murrell DF, Coroneo MT. Ophthalmic involvement in inherited epidermolysis bullosa. Dermatol Clin 2010;28:143-152.

12. Denyer J. Managing pain in children with epidermolysis bullosa. Nurs Times 2012;108:21-23.

13. Lin YC, Golianu B. Anesthesia and pain management for pediatric patients with dystrophic epidermolysis bullosa. J Clin Anesth 2006;18: 268-271.

14. Jeon IK, On HR, Kim SC. Quality of life and economic burden in recessive dystrophic epidermolysis bullosa. Ann Dermatol 2016;28:6-14.

15. Tabolli S, Pagliarello C, Uras C, Di Pietro C, Zambruno G, Castiglia D, et al. Family burden in epidermolysis bullosa is high independent of 
disease type/subtype. Acta Derm Venereol 2010;90:607-611.

16. Margari F, Lecce PA, Santamato W, Ventura P, Sportelli N, Annicchiarico G, et al. Psychiatric symptoms and quality of life in patients affected by epidermolysis bullosa. J Clin Psychol Med Settings 2010;17:333-339.

17. Andreoli E, Mozzetta A, Angelo C, Paradisi M, Foglio Bonda PG. Epidermolysis bullosa, psychological and psychosocial aspects. Dermatol Psychosom 2002;3:77-81.

18. Fortuna G, Aria M, Cepeda-Valdes R, Garcia-Garcia SC, Moreno-Trevino MG, Salas-Alanis JC. Role of dystrophic epidermolysis bullosa in anxiety, depression and self-esteem: a controlled cross-sectional study. J Dermatol 2016;43:70-78.

19. Fine JD, Johnson LB, Weiner M, Suchindran C. Assessment of mobility, activities and pain in different subtypes of epidermolysis bullosa. Clin Exp Dermatol 2004;29:122-127.

20. Marini I, Vecchiet F. Sucralfate: a help during oral management in patients with epidermolysis bullosa. J Periodontol 2001;72:691-695.

21. Frew JW, Cepeda Valdes R, Fortuna G, Murrell DF, Salas Alanis J. Measuring quality of life in epidermolysis bullosa in Mexico: crosscultural validation of the Hispanic version of the Quality of Life in Epidermolysis Bullosa questionnaire. J Am Acad Dermatol 2013;69:652653.

22. Melzack R. The short-form McGill Pain Questionnaire. Pain 1987;30: 191-197.

23. Lobo A, Chamorro L, Luque A, Dal-Re R, Badia X, Baro E, et al. [Validation of the Spanish versions of the Montgomery-Asberg depression and Hamilton anxiety rating scales]. Med Clin (Barc) 2002;118:493-499.

24. Ramos-Brieva JA, Cordero-Villafafila A. A new validation of the Hamilton Rating Scale for Depression. J Psychiatr Res 1988;22:21-28.

25. Comité de Redacciòn de la RID. Diagnòstico del dolor neuropatiàtico: un gran desafio. Rev Iberoamericana del Dolor 2007;3:48-54.

26. Burckhardt CS, Jones KD. Adult measures of pain. Arthritis Care Res 2003;49:S96-S104.

27. Mason VL, Skevington SM, Osborn M. Assessing the properties of the WHOQOL-Pain: quality of life of chronic low back pain patients during treatment. Clin J Pain 2010;26:583-592.
28. Wilkie DJ, Savedra MC, Holzemer WL, Tesler MD, Paul SM. Use of the McGill Pain Questionnaire to measure pain: a meta-analysis. Nurs Res 1990;39:36-41.

29. Hamilton M. The assessment of anxiety states by rating. Br J Med Psychol 1959;32:50-55.

30. Matza LS, Morlock R, Sexton C, Malley K, Feltner D. Identifying HAMA cutoffs for mild, moderate, and severe generalized anxiety disorder. Int J Methods Psychiatr Res 2010;19:223-232.

31. Hamilton M. A rating scale for depression. J Neurol Neurosurg Psychiatry 1960;23:56-62.

32. Zimmerman M, Martinez JH, Young D, Chelminski I, Dalrymple K. Severity classification on the Hamilton Depression Rating Scale. J Affect Disord 2013;150:384-388.

33. Uebelacker LA, Weisberg RB, Herman DS, Bailey GL, Pinkston-Camp MM, Stein MD. Chronic pain in HIV-infected patients: relationship to depression, substance use, and mental health and pain treatment. Pain Med 2015;16:1870-1881.

34. Gatchel RJ, Peng YB, Peters ML, Fuchs PN, Turk DC. The biopsychosocial approach to chronic pain: scientific advances and future directions. Psychol Bull 2007;133:581-624.

35. Ebesutani C, Chorpita BF, Higa-McMillan CK, Nakamura BJ, Regan J, Lynch RE. A psychometric analysis of the Revised Child Anxiety and Depression Scales--parent version in a school sample. J Abnorm Child Psychol 2011;39:173-185.

36. O'Rourke D. The measurement of pain in infants, children, and adolescents: from policy to practice. Phys Ther 2004;84:560-570.

37. van Scheppingen C, Lettinga AT, Duipmans JC, Maathuis CG, Jonkman MF. Main problems experienced by children with epidermolysis bullosa: a qualitative study with semi-structured interviews. Acta Derm Venereol 2008;88:143-150.

38. Moulin D, Boulanger A, Clark AJ, Clarke H, Dao T, Finley GA, et al. Pharmacological management of chronic neuropathic pain: revised consensus statement from the Canadian Pain Society. Pain Res Manag 2014;19:328-335. 